\title{
Влияние малых доз гамма-излучения на оптические свойства пористого кремния
}

\author{
() Д.И. Биленко, О.Я. Белобровая, Д.В. Терин, В.В. Галушка, И.В. Галушка, Э.А. Жаркова, В.П. Полянская, \\ В.И. Сидоров, И.Т. Ягудин
}

Саратовский государственный университет им. Н.Г. Чернышевского, 410012 Саратов, Россия

E-mail: lab32@mail.ru

(Получена 1 марта 2017 г. Принята к печати 29 июня 2017 г.)

Показана возможность модификации фотолюминесцентных свойств пористого кремния при облучении малыми дозами $\gamma$-квантов радиоизотопного источника ${ }^{226} \mathrm{Ra}$ и тормозного излучения. Положение максимальной длины волны фотолюминесценции (PL) имеет тенденцию сдвига в коротковолновую область спектра, эффективность излучения (PL) растет как при облучении подложки, так и образующегося слоя.

DOI: $10.21883 /$ FTP.2018.03.45620.8570

\section{1. Введение}

Пористый кремний (ПК) представляет собой материал, обладающий сильной люминесценцией в видимой области спектра при комнатной температуре [1-3]. В настоящее время значительное число работ в области современной опто- и наноэлектроники посвящено исследованию пористого кремния в силу его перспективных для практического применения фотолюминесцентных свойств [3-6]. Отдельной задачей является стабилизация и модификация указанных свойств пористого кремния, в число которых входит ионизационное гамма-облучение материала малыми дозами. Известно, что воздействие малых доз $\left(D=10^{3}-10^{5} \mathrm{P}\right)$ ионизирующих излучений, в частности $\gamma$-излучения, улучшает электрические и оптические свойства полупроводников. В основе объяснения этого эффекта лежит предположение об определяющем влиянии исходной дефектности кристалла на процессы, обусловленные радиационным воздействием. При этом предполагается, что на первом этапе воздействия преобладают преобразования точечных дефектов, результатом которых является снижение исходной дефектности [7-11].

Обзор опубликованных работ показал, что практически все экспериментальные исследования влияния $\gamma$-излучения на свойства пористого кремния, обладающего фотолюминесценцией (ФЛ) в видимой области спектра, проводились с помощью радиоизотопного источника ${ }^{60} \mathrm{Co}$, испускающего $\gamma$-кванты с энергиями 1.17 и $1.33 \mathrm{MeV}[6,12,13]$. Представляется интересным исследовать в более широкой энергетической (по сравнению с известными) области влияние малых доз облучения радиоизотопным источником ${ }^{226} \mathrm{Ra}$ и на пучке $\gamma$-квантов тормозного излучения на положение длины волны и эффективность фотолюминесцентного излучения пористого кремния и спектр комбинационного рамановского рассеяния, который позволяет выявить детали и особенности микроструктуры ПК. Это и является целью настоящей работы.

\section{2. Образцы и методика измерений}

Исследуемые слои пористого кремния получали при комплексном контроле технологического процесса. Облучению подвергались как подложки, с последующим получением на них ПК, так и слои ПК на необлученных подложках. Пористый кремний получался методом электрохимического травления. Состав электролита: 48\%-й раствор плавиковой кислоты-изопропиловый спирт в соотношении $1: 1$. В качестве анода служила подложка кремния, в качестве катода - платиновая проволока. Электрохимическая обработка проводилась в гальваностатическом режиме при плотности тока $8 \mathrm{MA} / \mathrm{cm}^{2}$. На основе разработанного метода контроля in situ [14] по спектральной зависимости коэффициента отражения определялись толщина и пористость образующегося слоя, которые составили 4-5 мкм и 75-80\% соответственно. При погрешности измерения коэффициента отражения не более 5\% погрешность измерения скорости роста и пористости 0.6 и $6 \%$ соответственно [14]. При одинаковом технологическом режиме для сравнения получались образцы пористого кремния без облучения исходной подложки.

Полученные образцы пористого кремния были разделены на 2 группы: группа А - ПК на облученной подложке, группа В - облученный слой ПК. Для сравнения исходным считался образец ПК на необлученной подложке и без облучения слоя. Радиационная обработка образцов осуществлялась двумя источниками: радиоизотопным источником ${ }^{226} \mathrm{Ra}$ (линейчатый спектр, максимальная энергия $E_{\gamma}=2.43 \mathrm{MэB)} \mathrm{в} \mathrm{специальной}$ камере и тормозным $\gamma$-излучением ускорителя электронов - бетатрона СГУ при максимальной энергии $E_{\gamma}=25$ МэВ. Образцы помещались в центре пучка на расстоянии $75 \mathrm{~cm}$ от платиновой тормозной мишени. Облучение проводилось на воздухе при температуpe $\leq 35^{\circ} \mathrm{C}$.

В качестве подложек для получения пористого кремния использовались образцы кремния различного уровня легирования. Для выяснения механизма воздействия 
$\gamma$-облучения на свойства пористого кремния исследовались спектры фотолюминесценции и комбинационного рассеяния (КРС). Спектры фотолюминесценции регистрировались на люминесцентном спектрофотометре LS55 PerkinElmer, длина волны возбуждающего света 330 нм при комнатной температуре. Использовалась геометрия скрещенных поляризаторов. Спектры комбинационного рассеяния света регистрировали на спектрометре Renishaw inVia с длиной волны лазера 785 нм, мощностью 0.5 и 0.05 мВт, временем экспозиции матрицы 10 с. Длина волны 785 нм обеспечивает отсутствие люминесцентного сигнала.

\section{3. Результаты и обсуждение}

Результаты обработки экспериментальных данных представлены на рис. 1, 2. На рисунках приведены спектральные зависимости спектров фотолюминесценции и
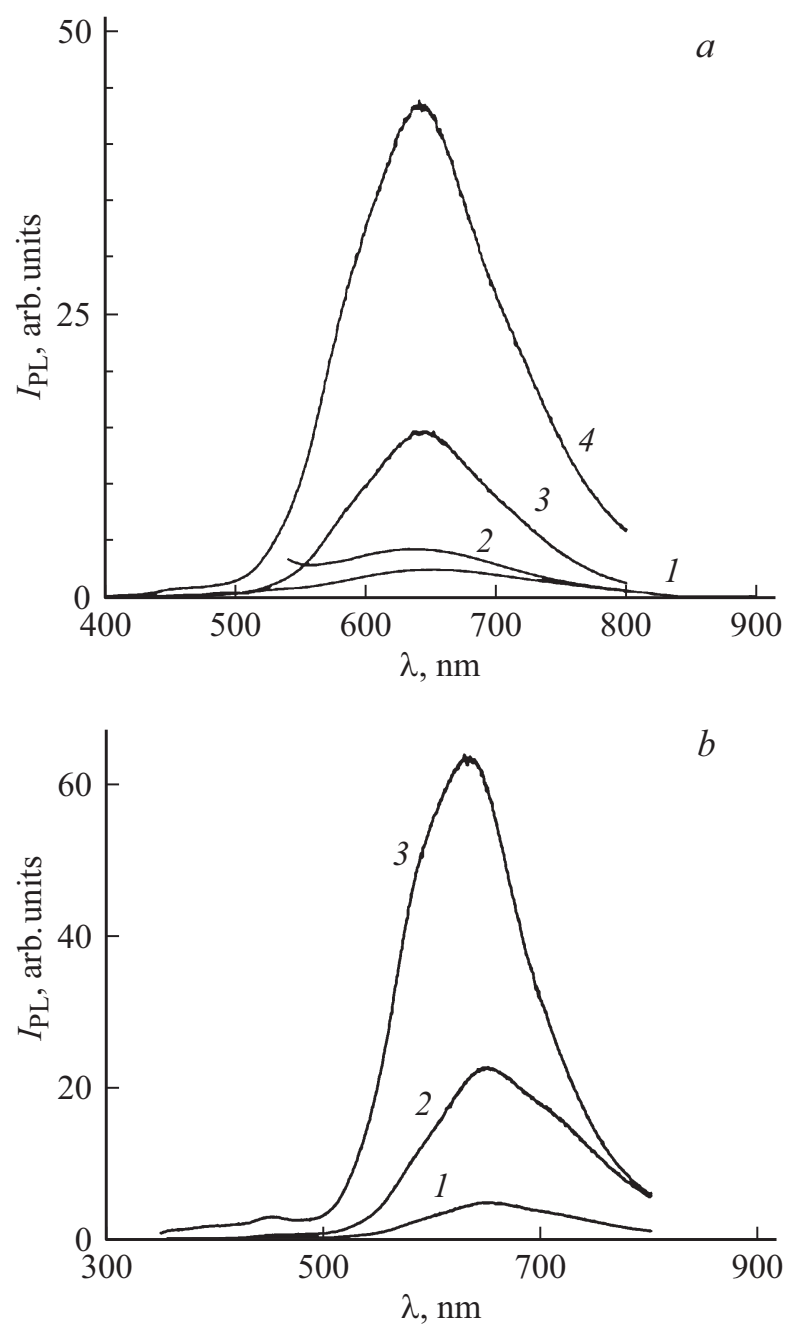

Рис. 1. Спектры фотолюминесценции образцов ПК при различных дозах облучения (кР): $a-$ группа А: 1 - исходный ПК, 2 - 38 (радиевый источник), $3-15$ ( $\gamma$-кванты), $4-38.4$, $(\gamma$-кванты $) ; b-$ группа В: 1 - исходный ПК, $2-11$ ( $\gamma$-кванты $), 1,3-20$ ( $\gamma$-кванты $)$.
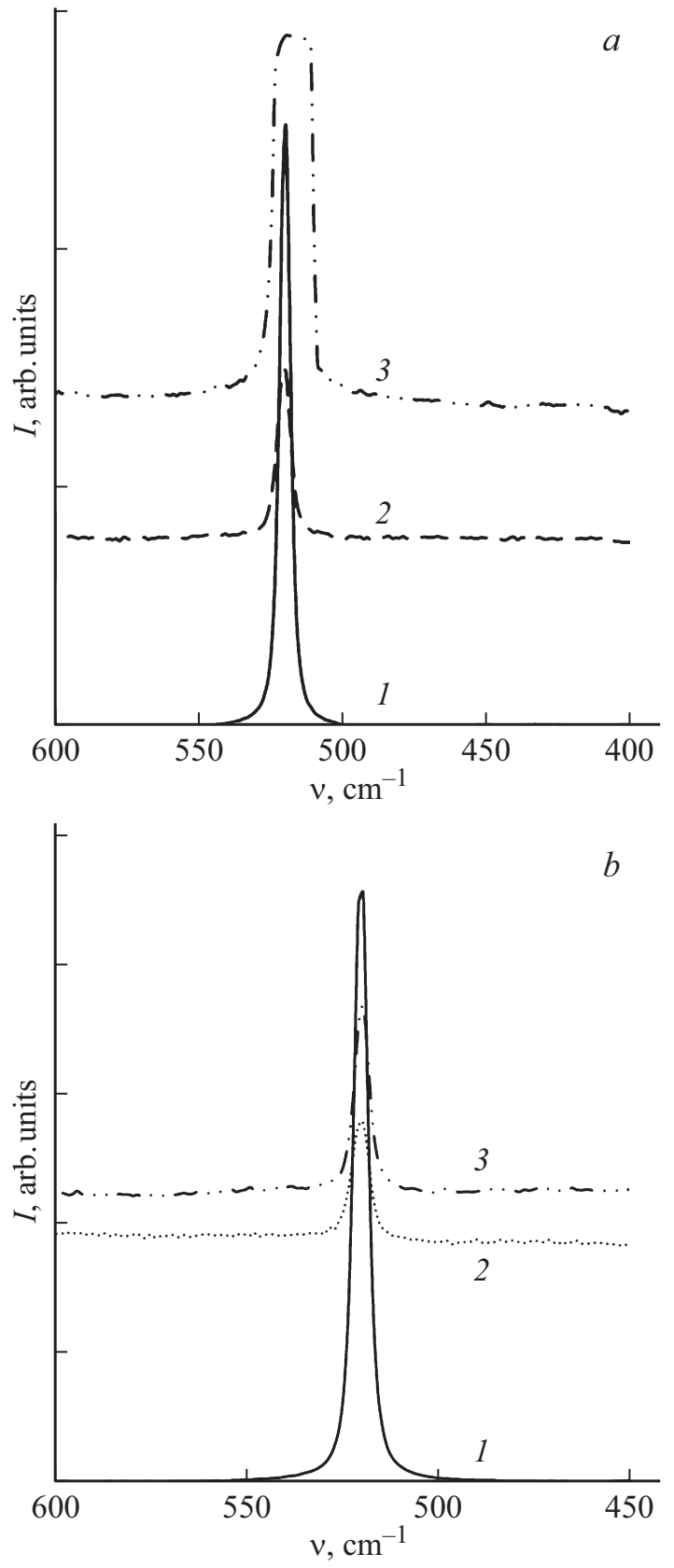

Рис. 2. Спектры комбинационного рамановского рассеяния образцов ПК при различных дозах $\gamma$-облучения (кР): $a-$ группа А: 1 - исходная подложка, $2-15,3-38.4 ; b-$ группа В: 1 - исходная подложка, $2-11,3-20$.

комбинационного рамановского рассеяния при различных дозах облучения подложки (образцы группы А) и слоя пористого кремния (образцы группы В). Аппроксимация полученных спектров ФЛ и КРС позволила найти спектральное положение максимумов и полуширины линий.

Получены следующие результаты.

Обнаружено, что при образовании слоя ПК временны́е зависимости скорости получения и пористости слоя ведут себя по-разному для образцов с подложкой, 
подвергнутой облучению различной дозой и без. На образцах пористого кремния, полученных на облученной подложке, временные изменения скорости роста слоя и пористости более стабильны, чем у необлученных. Установить это позволила детальная расшифровка интерферограмм in situ процессов образования ПК. Разброс значений скорости для облученной подложки составил $17 \%$ против $30-40 \%$ у образцов, полученных на необлученной подложке.

Таким образом, процесс получения пористого кремния более стабильный на облученных подложках. Этот факт может быть связан с понижением исходной дефектности кристалла кремния за счет облучения, что косвенно подтверждается и снятыми спектральными зависимостями ФЛ.

Спектры фотолюминесценции образцов групп А и В, приведенные на рис. 1 , характеризуются наличием широкой люминесцентной полосы в образцах обеих групп. Это может быть связано с квантово-размерным эффектом $[2,3,6]$. Относительное сопоставление интенсивностей в максимуме спектра ФЛ при одной поляризации света обнаружило увеличение сигнала при воздействии $\gamma$-квантов по сравнению с интенсивностью в исходном ПК (рис. $1, a, b)$. Люминесценция отличалась большой интенсивностью и была видна невооруженным глазом.

Для всех образцов спектральное положение максимума фотолюминесценции $\lambda_{\max }$ по отношению к $\lambda_{\max }$ исходного ПК незначительно сдвигалось в коротковолновую область, что согласуется с результатами работы [6]. Согласно нашим оценкам энергий квантования электронов и дырок, наблюдавшиеся энергии максимумов ФЛ от 1.88 до 2 эВ соответствуют размерам кристаллитов $L$ от 3.28 до 3.18 нм. Кристаллиты такого размера вносят, вероятно, основной вклад в ФЛ. При этом на положение $\lambda_{\max }$ для образцов группы А не сказывается тип источника облучения, характеризующегося различной энергией $\gamma$-квантов. Среди облученных образцов наблюдается слабая зависимость спектрального положения полосы ФЛ ПК от дозы для обеих групп. Это указывает на тот факт, что свойства центров излучения практически не изменяются под действием ионизирующего излучения. Увеличение интенсивности ФЛ в модифицированных при облучении $\gamma$-квантами образцах обеих групп пористого кремния и сдвиг в коротковолновую область $\lambda_{\max }$ могут быть обусловлены вкладом образующихся нанокристаллитов. Этот факт подтверждается появлением левого плеча в спектрах ФЛ образцов группы А и В (рис. 1).

Полуширина полосы $b$ полосы PL существенно уменьшалась по сравнению с исходным образцом ПК от 0.3 до 0.2 эВ. Уменьшение полуширины полосы спектра ФЛ по сравнению с исходным ПК в образцах групп А и В при облучении $\gamma$-квантами свидетельствует об исчезновении крупных кристаллитов. Это можно отнести к большей однородности полученного слоя ПК, что подтверждается данными контролируемых процессов получения.
Спектры КРС, записанные для образцов группы А и $\mathrm{B}$, приведены на рис. $2, a, b$. Как следует из рисунков, наблюдалось красное смещение спектрального положения максимума $P_{1}-\omega_{P 1}$ ПК в низкочастотную область $\left(511-519 \mathrm{~cm}^{-1}\right)$ относительно максимума пика $P_{1} c$-Si $\left(520 \mathrm{~cm}^{-1}\right)$. Полуширина $b$ полосы пика $P_{1}$ ПК увеличивалась относительно ее значения для кристаллического кремния (см. рис. 2). Для образцов группы А (рис. 2,a) интенсивность $P_{1}$ пористого кремния, полученного на облученных подложках при различной дозе, уменьшалась вдвое относительно интенсивности $P_{1}$ облученных подложек (рис. 2,a).

Интенсивность пика $P_{1}$ для образцов группы В максимальна для подложки. По мере роста дозы облучения от 11 до 20 кР интенсивность падает почти в $2-3$ раза относительно подложки.

Падение интенсивности КРС при облучении $\gamma$-квантами для обеих групп образцов в сочетании с ростом полуширины основной полосы может быть обусловлено нарушение правил отбора для рамановского рассеяния из-за разрыва связей и смещения положительного заряда, изменением оптических свойств материала, что может привести к росту коэффициента поглощения на длине волны возбуждения $[3,14,15]$. Возникающая поверхностная шероховатость в области облучения может привести к росту рассеяния и непопадания луча в объектив.

Величина смещения спектрального положения пика $P_{1}$ относительно кристаллического кремния $\Delta \omega=$ $=\omega_{P_{1}, c-\mathrm{Si}}-\omega_{P_{1} \text { Пк и }}$ его полуширина позволили оценить размер нанокристаллита $L$ в пределах модели фононного ограничения [16-18]. Размеры нанокристаллитов группы А составили 3-10 нм, для образцов группы В значения $L$ находились в пределах $3-6$ нм в отличие от исходного ПК $(L=12 \mathrm{Hм})$.

\section{4. Заключение}

Исследовано влияние малых доз облучения в более широкой энергетической (по сравнению с известными) области радиоизотопным источником ${ }^{226} \mathrm{Ra}$ и на пучке $\gamma$-квантов тормозного излучения на положение длины волны и эффективность фотолюминесценции и спектр комбинационного рамановского рассеяния пористого кремния.

Облучение подложки перед процессом формирования ПК и отдельно только образованного слоя малыми дозами $\gamma$-квантов ${ }^{226} \mathrm{Ra}$ и тормозного излучения ускорителя электронов позволило выявить детали и особенности микроструктуры ПК и обнаружить, что результатом модифицирующего воздействия стало формирование нанокристаллитов меньшего диаметра по сравнению с исходным ПК.

Авторы выражают благодарность И.Б. Мысенко, Т.Е. Мельниковой, Д.Н. Браташову, В.И. Кочубею за помощь в проведении исследований. 
Работа выполнена при частичной поддержке Министерства образования и науки РФ (базовая часть государственного задания) и финансовой поддержке РФФИ в рамках научного проекта № 18-07-00752.

\section{Список литературы}

[1] A. Roy, K. Jayaramб A.K. Bull. Matter. Sci., 17, 513 (1994).

[2] В.В. Ушаков, В.А. Дравин, Н.Н. Мельник, В.А. Караванский, Е.А. Константинова, В.Ю. Тимошенко. ФТП, 31, 1126 (1997).

[3] И.И. Решина, Е.Г. Гук. ФТП, 7, 728 (1993).

[4] В.А. Юзова, А.А. Левницкий, П.А. Харлашин. Журн. Сибирского федерального ун-та, 4, 102 (2011).

[5] А.С. Леньшин, В.М. Кашкаров, П.В. Середин, Б.Л. Агапов, Д.А. Минаков, В.Н. Ципенюк, Э.П. Домашевская. ЖТФ, 84, 70 (2014).

[6] Е.В. Астрова, Р.Ф. Витман, В.В. Емцев. ФТП, 30, 507 (1996).

[7] А.П. Мамонтов, И.П. Чернов. Эфбект малых доз ионизирующего излучения (Томск Дельтаплан, 2009).

[8] И.П. Чернов, А.П. Мамонтов, И.А. Коротченко. ФТП, 14, 2271 (1980).

[9] И.П. Чернов, А.П. Мамонтов, П.А. Черданцев. Изв. вузов. Физика, 12, 58 (1994).

[10] И.П. Чернов, А.П. Мамонтов. Изв. Томского политехн. унта, 303, 74 (2000).

[11] В.К. Комарь, С.В. Сулима, О.Н. Чугай. Письма ЖТФ, 37, 1 (2011).

[12] Е.В. Астрова, В.В. Емцев, А.А. Лебелев, Д.И. Полозкин, А.Д. Ременюк, Ю.В. Рудь, В.Е. Харциев. ФТП, 29, 1301 (1995).

[13] Ismail Khalaf Abbas, Laith Ahmen Najam, Abd Ulkkahliq AuobSulaiman. Int. J. Phys., 3, 1 (2015).

[14] D. Bilenko, O. Belobrovaja, E. Jarkova, O. Coldobanova, I. Mysenko, E. Khasina, V. Polyanskaya, T. Melnikova, V. Smirnov, G. Filippova. Sensors Actuators A, 79, 147 (2000).

[15] Б.М. Булах, Б.Р. Джимаев, Н.Е. Корсунская, О.С. Литвин. ФТП, 36, 587 (2002).

[16] Zi Jian, Zhang Kaming, Xie Xide. Phys. Rev. B, 55, 9263 (1997).

[17] Yuliang He, Chenzhong Yin, Guangxu Cheng, Luchun Wang, Xiangna Liu. J. Appl. Phys., 75, 797 (1994).

Редактор Г.А. Оганесян

\section{Influence of small doses of gamma radiation on the optical properties of porous silicon}

\author{
D.I. Bilenko, O.Ya. Belobrovaya, D.V. Terin, \\ V.V. Galushka, I.V. Galushka, E.A. Zharkova, \\ V.P. Polyanskaya, V.I. Sidorov, I.T. Yagudin
}

Saratov Chernyshevsky State University, 410012 Saratov, Russia

\begin{abstract}
The possibility of modification of the photoluminescent properties of porous silicon under irradiation with a small dose of gamma quanta of a ${ }^{226} \mathrm{Ra}$ radioisotope source and bremsstrahlung is demonstrated. The position of the maximum wavelength of photoluminescence (PL) tends to shift to the shortwavelength region of the spectrum. The efficiency of PL radiation increases, when the substrate before the process and only formed layer are irradiated. The efficiency of the radiatian increases, both when the substrate is irradiated and the layer formed.
\end{abstract}

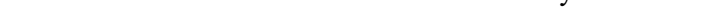

